\title{
Building a Platform for Knowledge Engagement: Sowing Seedlings in New Media
}

\author{
Nurhazman Abdul Aziz \\ Library \\ Nanyang Technological University \\ Singapore \\ nurhazman@ntu.edu.sg
}

\author{
Margaret Tan \\ Wee Kim Wee School of Communication and Information \\ Nanyang Technological University \\ Singapore \\ mtan@ntu.edu.sg
}

\begin{abstract}
Building a platform for knowledge creation and engagement is a big task for librarians especially when incorporating social or new media. But, with the advent of new tools and open source technology, the librarians at Nanyang Technological University are able to sow the seeds in the library's technology infrastructure. The initiative leads in the construction of a campus wide platform, adopting WordPress architecture to strategically align with its online information service. Subject guides are now able to reinvent the traditional reference services into a new way of seamless outreach and digital engagement. Seeds of engagement are sowed as the project team provides a platform of flexibility and interoperability for content creation.
\end{abstract}

Keywords: Library Science, knowledge creation, digital engagement, new media, information techology

\section{INTRODUCTION}

With the advent of new tools and open source technology, libraries are keen to use new media to support its users. Indeed, a key strategic pillar especially that of academic libraries, is to implement 'Library 2.0' or web 2.0 to provide a new approach to service its readers. A common initiative is to build a blog among the librarians to create knowledge awareness and morph it into knowledge engagement as part of their digital information service (or digital advocacy).

Weblogs (or commonly known as blogs) are increasingly popular in today's online community and they have surged since the early times (Nardi, Schiano, Gumbrecht, \& Swartz, 2004). This is due to the ease in which the site can be created and that participants are then able to share the knowledge (or idea) with the community. For instance, the librarians would adopt such practice of digital advocacy, creating a library blogo-sphere that in turn may lead to the adoption of social web.

The nature of social web allows everyone (including the librarians) to create a post, publish, and getting feedback from the community on the idea, product or services that they share. In fact, the processes in digital engagement have led to a number of a number of online tools and platforms which people share their perspectives, opinions, thoughts, and experiences (Nardi, et al., 2004; Torres-Salinas, CabezasClavijo, Ruiz-Pérez, \& López-Cózar, 2011). Interestingly, the platform has morphed tremendously fast over the last decade, from simple blogs' architecture to the fast development tools for social networking (e.g., Facebook and Twitter). In fact, the the social networking tools are shifting into a competitor stage for blogs as primary communications and media tools on the Internet. Libraries are also aware that the popularization of blogs is still a free platform such as Blogger and WordPress, which is easy to manage (Lackie \& LeMasney, 2008).

At Nanyang Technological University (NTU) Library, senior management is aware of the potential strength in having blogs as part of their digital advocacy as well as knowledge creation for their academic communities. Further, blogs have played a key role in structuring online professional communities, demonstrating the knowledge of each librarian, especially if he or she is a subject librarian (Kamel, Maramba, \& Wheeler, 2006). In 2010, a team of library technologists was formed at NTU and the team was tasked to look into the potential of building a new media platform for knowledge creation, development, management, engagement and immersive for the librarians (particularly subject librarians). On this platform, subject librarians are able to perform their digital advocacy in their subject domain knowledge sharing the library resources (the heartland) to their patrons (academic and student communities) in a semantic approach. If the model works for the subject librarians, the service would be expanded to the facilities and administration department, putting a suitable operating model as part of their strategic digital advocacy, outreach or awareness (Bonetta, 2007; Eastment, 2005). Indeed, via this approach, the idea of community or social involvement/engagement is now seeded and harvested. Thus, the objective of this paper is to share the initiative (through experiential learning) and the potential of building the blog platform towards harvesting digital advocacy.

\section{THE KNOWLEDGE PLATFORM}

\section{A. The Task Team - Library Technologist' discovers...}

The idea of creating a blog platform was initiated in late 2006, upon the request by the University Chief Librarian. The basic objective is to serve the internal communication of the librarians' knowledge and awareness of the new social media (in term of social media literacy or new media literacy).

At that point of time, the approach was simple, that is, for (i) the librarians to perform their daily information scanning 
(either in their work or at leisure). Once, (ii) the librarians discover an interesting topic (in any form of media formats) on the Internet, (iii) they would follow up with a simple write up and post it on the blog. Following the write-up, (iv) other librarians would read the blogs having been notifying via the Really Simple Syndication (RSS or daily visit to the site). They would then make comments or feedback based on their professional knowledge. Hopefully, (v) such postings and comments would then evolve a blogging culture in the science library to improve or enhance on the librarians' professional development (Hendricks, 2010; Laning, Lavallée-Welch, \& Smith, 2005; Stephens, 2008). The process flow is illustrated in Figure 1.

\section{Librarians' Professional Knowledge Development}

\begin{tabular}{|l|l|}
\hline (i) Knowledge Awareness & \\
\hline (ii) Knowledge Management (Creation) & \\
\hline (iii) Knowledge Development & \\
\hline (iv) Knowledge Immersive & \\
\hline
\end{tabular}

Figure 1 - Daily activities capture in a flow chart

As the process illustrates a professional knowledge development which is currently taught in library school (Foo \& $\mathrm{Ng}$, 2008), the task team adopted a potential knowledge management approach. Similar to the library school in United States, Aharony (2008) suggested the best way to develop in learning, practicing and sharing is not through an individual; in fact, the team identified that new media platform would be most ideal to facilitate the activities and interaction so that digital engagement can be achieved towards accomplishing the end results.

\section{B. Seeding the platform for ...}

The first plan is to identify and seed a suitable platform for knowledge creation and engagement. The team understands the importance and rising significant of blogging culture in the library science industry (Noa Aharony, 2009; Kesselman \& Watstein, 2009; Laning, et al., 2005; Stephens, 2008; Svensson, 2010). As there are two prominent platforms commonly adopted by libraries such as Blogspot and WordPress, Lackie \& LeMasney (2008) made a detailed comparison between these two platforms based on the services focus, features and feel. In order to ensure that the platform is suitable for our development, we analyse whether the key components/features (the seeding) are checked based on the following various criteria:-
1. Audience Centric
2. Administration Centric
3. Portability
4. Content Creation
5. Extra Site Relation
6. Common Management
7. Design
8. Media Management

The eight key components will serve as the seeds to harvest the digital ecosystem to take in place at NTU library.

\section{Elaborating on the seeds...}

With the eight key components identified as seeding requirements, in fact, they are actually the basic characteristics (or attributes) in a given blogging engine. Although some of the terms may not be comprehensive, nevertheless they allow a conversational understanding of the most common, useful or popular features that are available as well as being up to date (Lackie \& LeMasney, 2008).

Audience Centric feature refers and allows online readers to participate in various ways, such as (i) via RSS and Atom Feeds, (ii) syndication and aggregation, (iii) podcasting, (iv) tagging, (v) searching, (vi) commenting and (vii) sharing to other site. In order to foster a robust Audience Centric feature, Webster \& Ksiazek (2012) share theoretical framework for understanding fragmentation and advocate for more audiencecentric studies in today's web site component. This is because audience fragmentation is often taken as evidence of social polarization, which leads to a high possibility of digital engagement. Thus, the selected platform must be flexible, modular and scalable to facilitate such requirements.

Administration Centric feature refers and allows blog administrators (or owners) to perform their job in an effective way such as (i) the ability to have multiple authors, (ii) user management, (iii) post moderation and workflow, (iv) email notification and (v) dashboard system. Lindahl \& Blount (2003) share that web technologies, such as weblog management system has to be a consumer - producer role model. Historically, according to this model for web publishing, content consumers needed minimal skills and resources, while producers required production expertise and sophisticated tools to control content presentation and substance. As to address the requirements, it is important that the team focuses in addressing such situation initially.

Portability feature is one of the pertinent requirements to allow scalability of the platform by moving the content from one platform, engine or database to another. This concern the (i) license, (ii) standards, (iii) proprietary and (iv) import/export of content. In certain blogging platform, such as WordPress and Blogspot, the issue of portability is well explained technically on social network and data portability using semantic web by Bojars, Breslin \& Decker (2008) and also Lackie \& LeMasney (2008). The team also identified the possibilities of doing a mash up between the platform and 
social networks, such as Facebook and Twitter. This can be a great advantage as it can lead to a viral digital engagement, making the platform visible on the Internet and searchable.

Content Creation feature can be classified to be the main focus of the platform. It is concerned with allowing the blog authors to create posts and other types of content. The requirements such as (i) email entries (apart from log into browser and create a post), (ii) draft status, (iii) time stamping, (iv) bookmarklets, (v) media management and (vi) uploading and support have to be met. The main goal of building this platform is to ensure that there are such features as the ease of content creation, user-friendly interfaces and presentations (Gwynn, 2009; Mitchell \& Gilbertson, 2008). It is to be expected that there will be a higher acceptance level if the technology is easy to use.

Extra Site Relation feature allows the platform (down to a blog level) to be connected to other blogs, services and sites. This can be done via (i) trackback pings, (ii) links (data), (iii) micro format and (v) blog rolls and increase the connectivity and visibility of each blog for digital engagement.

Comment Management feature addresses the audience's feedback and interaction on the site. This is a function that can be done via (i) comments, (ii) per-post comment availability, (iii) spam to prevent unsolicited comments, (iv) moderation and (v) threaded discussion. It is one of the visual results of a digital engagement has taken in place (Hsu \& Lin, 2008).

Design feature enhances the aesthetic creativity with the function such as color, look, feel and layout of the blog. This is based on the creativity approach in (i) templates and themes, (ii) layout, (iii) cascading style sheets and (iv) plugins designed and coded by the blog developer or even as simple as the arrangement self-made by the blog administrator themselves. With this, the platform can be further explored to another level of blog services.

\section{The seeds (Blogspot or WordPress) as a platform}

Lackie \& LeMasney (2008) have described both the potential and disadvantage of Blogspot or WordPress as the preferred platform. After studying the versatility of the platform architecture, the preferred choice for the team is WordPress. It is due to the complexity and sophistication of the WordPress dashboard that is not present in the Blogger Dashboard. Indeed, this sophistication has the potential to delight the initiated and yet frustrate the normal, simple bloggers (Marci De, 2010; Brockmeier, 2010; Jones \& Farrington, 2011a). Since the last eight years, WordPress has continued in the open source tradition by unveiling all the source code it is built on, so as to encourage the community to provide inputs in its development. From the Codex that holds its technical information to the flurry of activity in the support forums, community involvement is what drives the innovations within WordPress's core architecture that contributes its modular and agility of the system to be deployed beyond more than just a blogging platform (Jones \& Farrington, 2011a).

Although WordPress is fundamentally blogging software, it is possible to scale it up beyond just blogging software. The team has analyzed its potentials to aim it into a comprehensive social networking platform by installing, BuddyPress (Matthew \& George, 2011). This will then allow the team to enable a potential start for digital engagement to take in place. This is because the platform will have completely customizable user profiles, user groups, forums, and many more social elements. In the near future, WordPress may have more explicit push and a streamlined workflow - for user-created content on WordPress sites (Jones \& Farrington, 2011a). Further, it allows for aggregation of content from non WordPress sites (such as Twitter, Facebook and other social media site). It also provides more flexibility and interoperability of content creation from one site to another.

\section{BUILDING FOR OUTREACH \& ENGAGEMENT}

The main objective of the project is to build a platform for knowledge creation and engagement based on the knowledge awareness that have been studied and specified on the selected open source technology. The team needs to take note of the community building capacity so as to develop the platform to cater for changes. Based on Vanclay et al. (2004)'s framework, and with an understanding of the decision-making at all phases of the initial project design, the team evaluates the platform so as to provide:

(1) the effectiveness of each outreach activity in meeting academic and students' objectives, including community participants towards the learning experience;

(2) the potential in each activity so as to increase participation in the activity and other activities associated with learning cultural heritage or resources; and

(3) the progress towards "the higher purpose", that is, the potential for such activities to affect learning or research resource management outcomes in the long term.

In especially academic libraries, creating web subject guides are well known among reference libraries. A subject guide is usually mistaken to know the laundry list of every reference book or Internet links related to a topic. But instead it is a truly useful subject guide. It is a list of carefully selected resources that will help library patrons (online users) to find the information they are looking for towards certain topic. It can consists of the key elements of a subject, ranging from the format of catalog, reference/books, indexes/databases, journals/magazines, government documents, web sources and others media format. Once these subject guides are created, there are five most pertinent points to take note (Fichter, 2005):

\section{Keep it on topic}

2. Do not overwhelm the users with exhaustive lists

3. Make the subject guide specific to your library

4. Be sure and clear with example

5. Be creative and have fun!

Usually librarians designed their subject guide as a webpage. As for NTU Library, the librarians started this initiative on a Hyper Text Markup Language (HTML) file. Many librarians found difficulties in developing website by writing HTML codes. A suitable solution is to harness on the 
strength of blog's anatomy (Miller, 2009; Mongkolwat, Kogan, Koh, \& Channin, 2005). Indeed, in the last decade, Morris \& Bosque (2010) share that the characteristics of subject guides/librarians have not changed drastically, despite the pace of change with the Web. It will be efficient and effective if Blog platform (such as WordPress) are adopted and introduced as part of libraries online service. Librarians will then not have the big learning curve in pick up new knowledge, but just to focus on the content creation. With these set of requirements, the team has only to focus on the ease of technical requirements in building for outreach and engagement. Figure 2 shows an example of a way to outreach and engage via video embedded approach to the site and also to supplement the learning experience in a visual motion graphics.

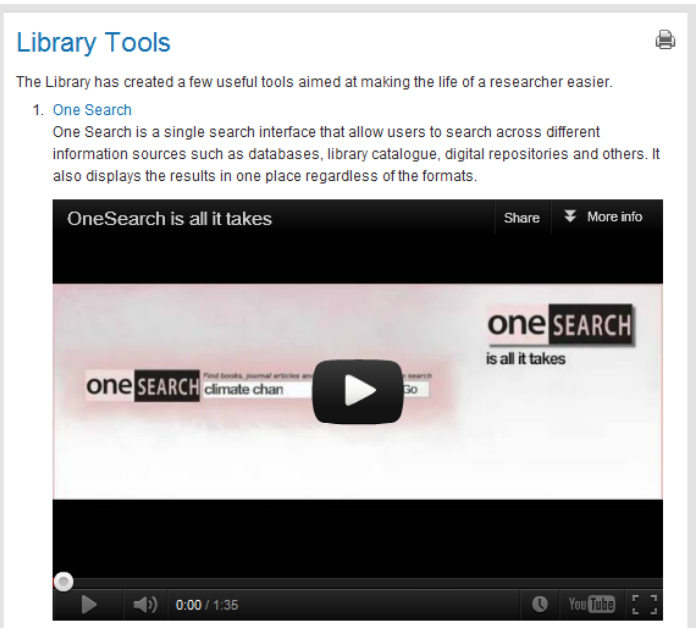

Figure 2 - Video embeded into WordPress Platform

Lackie \& LeMasney (2008) explained the strength of WordPress' for the audience's outreach and engagement via eight seeds. Jones and Farrington (2011b) elaborated that WordPress has such capabilities and fully described and demonstrated in Miller's (2009) web 2.0 for librarians and information. As the team is able to make the platform flexibility and interoperability of content created from one site to another, this will be a positive progression to capture the activities on outreach and engagement. Furthermore, these can be justified via the means of capture statistic report via Google Analytics, based on per click, searching terms, navigation patterns too and other measurement of requirements.

\section{THE EXPERIMENTAL KNOWLEDGE TOWARDS ENGAGEMENT}

For NTU Library, the team has created 30 subject guides (or subject rooms) as the base and located at this site web address, http://ntu.edu.sg/library/collections/Pages/virtual.aspx. Contents are created based on the knowledge and resources that library has to offer to the users, as illustrated in Figure 3. In addition, the contents are done in various formats (video, audio, info-graphics, etc.) and some of them are pulled from various site aggregation, such as YouTube (http://youtube.com) or Slide Share (http://slideshare.net).

Each site (or subject rooms), as shown in Figures 4 and 5, are also open to the commonly search engine via the search engine optimization. This is where the search engines index and harvest the entire contents of the platform. Through this, user can search easily using any commonly search engine such as Google, Yahoo and Bing to locate the resources that is created and shared by the subject librarians. And, via this, users can also place their comments, share their feedback and engage with the subject librarians on the elaborated resources.

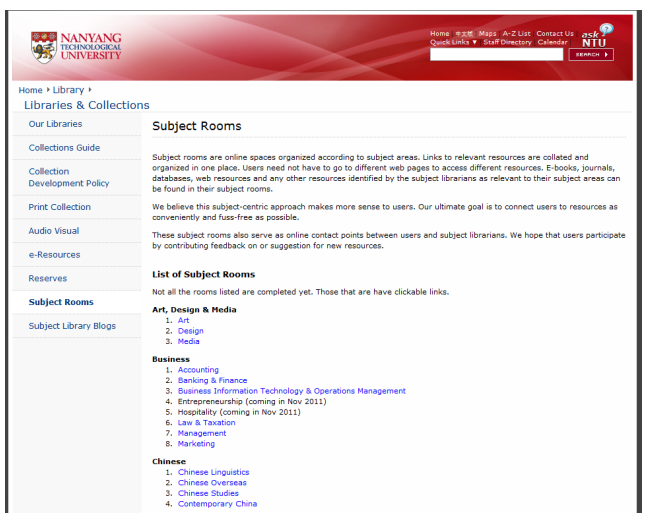

Figure 3 - Subject Rooms Directory

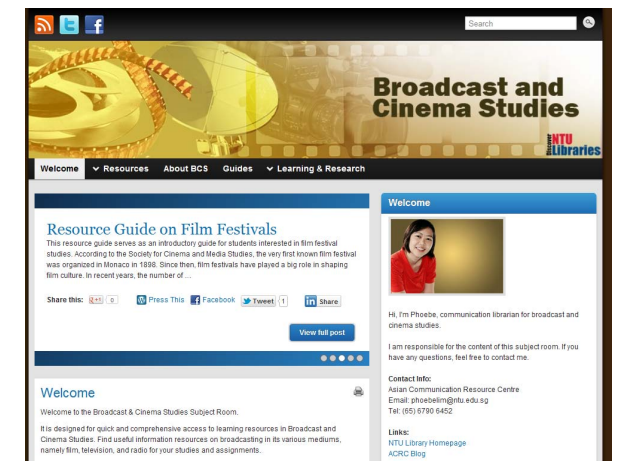

Figure 4 - Subject Rooms - Broadcast and Cinema Studies

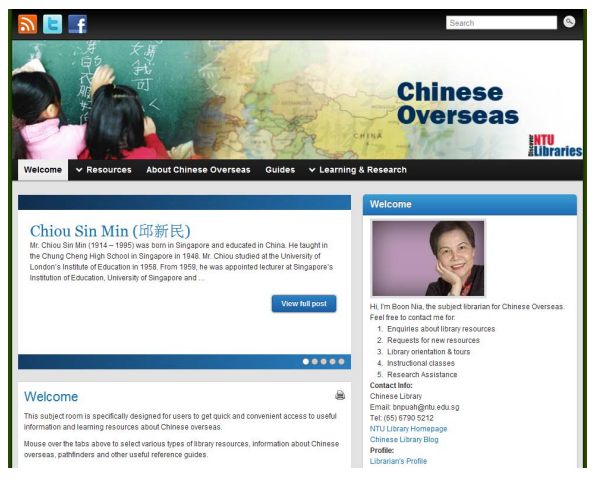

Figure 5 - Subject Rooms - Chinese Overseas

In advance, the team also has integrated it with Open Graph Protocol, to make the content of the platform match with the social graph and index to Facebook APIs. Through this work, the platform activities are socially captured and shared with the Facebook's domain, as illustrated on Figure 6. In addition, the user can share the content via their favorite websites too, such as Linkedin, Twitter and many more. In short, knowledge is now being shared and mobilized from one platform to another 
making the site viral. And, this is just apart from normal commenting process in a traditional out of the box blog packages that WordPress provides.
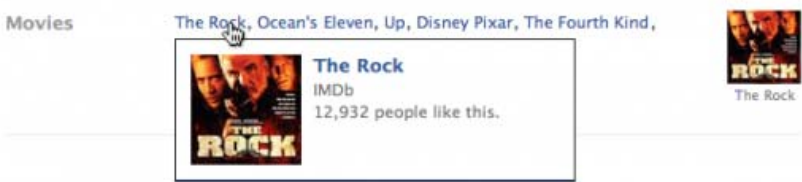

Figure 6 - Facebook delivered via WordPress Integration.

Further, the real benefits of using Open Graph Protocol is to enable users to easily find and interact with the content that Librarians have created. Another excellent feature of enabling on their subject gudies for the Open Graph is they will be able to gain valuable insights into their website visitors. They will be also be able to view these metrics right on Facebook as an example below, as shown in Figure 7.

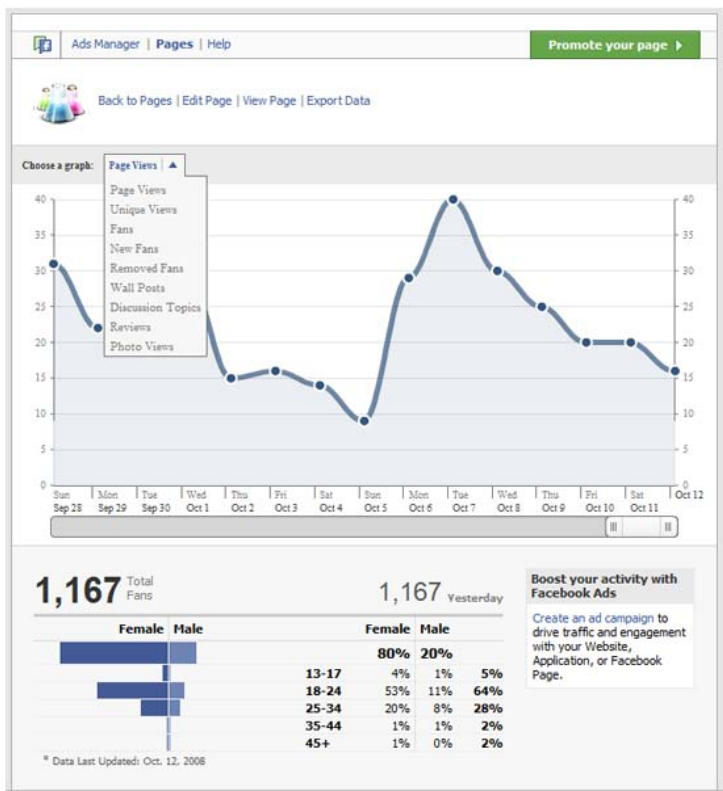

Figure 7 - Statistic caputured in Facebok that is shared and discussed.

\section{THE IMMERSION (DigITAL ENGAGEMENT)}

In terms of immersion, the platform is now sitting just like any other ordinary blog site. Users can just search using preferred search engines, such as Google. When they landed on to these subject guides, they will be referred back to the library actual core resources. Thus, the process creates an information concierge model. The librarians have to keep up with the update of the content and continue to play their useful role. They now break out from the traditional mould by re-inventing themselves and find ways to be part of the user's lives in the way they live them, instead of trying to getting the users to come to its physical and digital spaces (Foo, Ng, \& A., 2008). This is the first process of immersive that the team likes to achieve as this is also apart from the normal blogging system.
Next, the team would also like to take measures of the immersive results that will rise from the experimental knowledge towards the engagement. Posting can be shared as they appear on many social sites, trackback to be notified as other blogger cited or reference to the subject guides. Finally, it would be interesting to capture statistics on the engagement and outreach details.

\section{CONLUSION}

Like any other blogging system, content is the primary factor of this initiative. Librarians (content creator/blog administrator) must have:

1. the ease of the platform to create content

2. the understanding where the posting is to appear, apart from just the blog

3. the ability to search and index by common search engine

4. the tool to capture the statistic of where the content is being shared and engaged

5. the visual graphic presentation of the engagement.

The above 5 priorities are needed to be addressed before any enhancement could be made or suggested. Hence, the creation of knowledge awareness could take place virally and also foster the outreach and refine further the digital engagement processes.

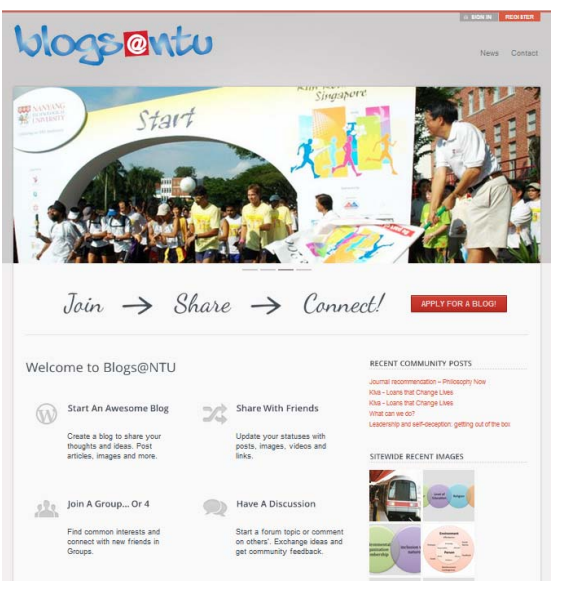

Figure 8 - The landing page at http://blogs.ntu.edu.sg

In conclusion, this project is still an on-going process and can be located at http://blogs.ntu.edu.sg, and is illustrated in Figure 8 . The team has created communities of blogosphere for the past one year. Indeed, this is one of the potential ways for librarians to communicate their resources to the community. These activities can then be a role model for academics and the university community to enter the blogosphere and ride on the elements of digital engagement using social media. Meanwhile, the team is refining and citing examples to build a social platform similar to other social website, like Facebook, but to cater to the university's academic and community needs. 


\section{ACKNOWLEDGMENT}

This project was initiated by my team members during our Master of Science (Information Studies) course and adopted by the library to be implemented campus wide. We are now at our $16^{\text {th }}$ month running this project and working towards a full scale in building a social media platform, like WordPress.com.

\section{REFERENCES}

[1] Aharony, N. (2008). Web 2.0 in U.S. LIS schools: Are they missing the boat? Ariande(54).

[2] Aharony, N. (2009). Librarians and information scientists in the blogosphere: An exploratory analysis. Library \& Information Science Research, 31(3), 174-181.

[3] Bojars, U., Breslin, J., \& Decker, S. (2008). Social Networks and Data Portability using Semantic Web technologies. Paper presented at the 2nd Workshop on Social Aspects of the Web (SAW 2008), in conjunction with 11th International Conf on Bus Information Systems (BIS 2008).

[4] Bonetta, L. (2007). Scientists Enter the Blogosphere. Cell, 129(3), 443445.

[5] Eastment, D. (2005). Blogging. ELT Journal: English Language Teachers Journal, 59(4), 358-361.

[6] Fichter, D. (2005). Designing a Better Subject Page to Make Users' Searches More Successful. Computers in Libraries, 25(9), 6-56.

[7] Foo, S., \& Ng, J. (2008). Library 2.0, Libraries and Library School. Paper presented at the Proc. Library Assoc of Singapore Conference.

[8] Foo, S., Ng, J., \& A., S. (2008). Going Virtual for Enhanced Library Experience: a Case Study of the National Library of Singapore. Paper presented at the VALA 2008, Melbourne, Australia.

[9] Gwynn, D. (2009). Open Source Web Content Management Systems in a Library Environment. from http://davidgwynn.com/pdf/631_final.pdf

[10] Hendricks, A. (2010). Bloggership, or is publishing a blog scholarship? A survey of academic librarians. Library Hi Tech, 28(3), 470-477.

[11] Hsu, C.-L., \& Lin, J. C.-C. (2008). Acceptance of blog usage: The roles of technology acceptance, social influence and knowledge sharing motivation. Information \&amp; Management, 45(1), 65-74.

[12] Jones, K., \& Farrington, P. (2011a). Chapter 1: Getting Started with WordPress. Library Technology Reports, 47(3), 8-15.

[13] Jones, K., \& Farrington, P. (2011b). WordPress as Library CMS. American Libraries, 42(5/6), 34.

[14] Kamel, M.I., \& Wheeler, S. (2006). Wikis, blogs and podcasts: a new generation of Web-based tools for virtual collaborative clinical practice and education.
[15] Kesselman, M. A., \& Watstein, S. B. (2009). Creating Opportunities: Embedded Librarians. Journal of Library Administration, 49(4), 383400.

[16] Lackie, R. J., \& LeMasney, J. W. (2008). Blogger, WordPress.com, and Their Pseudoblog Alternatives: A Comparison of Focus, Features, and Feel. Journal of Library Administration, 46(3-4), 139-180.

[17] Laning, M., Lavallée-Welch, C., \& Smith, M. (2005). Frontiers of Effort: Librarians and Professional Development Blogs. Journal of Library Administration, 43(3/4), 161-179.

[18] Lindahl, C., \& Blount, E. (2003). Weblogs: simplifying web publishing. Computer, 36(11), 114-116.

[19] Matthew, G., \& George, O. (2011). The CUNY Academic Commons: fostering faculty use of the social web. [DOI: 10.1108/10748121111107681]. On the Horizon, 19(1), 24-32.

[20] Miller, R. (2009). Web 2.0 For Librarians and Information Professionals. Technical Services Quarterly, 26(3), 257-258.

[21] Mitchell, E., \& Gilbertson, K. (2008). Using Open Source Social Software as Digital Library Interface. D-Lib Magazine, 14(3/4).

[22] Mongkolwat, P., Kogan, A., Koh, J., \& Channin, D. (2005). Blogging Your PACS. Journal of Digital Imaging, 18(4), 326-332.

[23] Morris, S. E., \& Bosque, D. D. (2010). Forgotten Resources: Subject Guides in the Era of Web 2.0. Technical Services Quarterly, 27(2), 178193.

[24] Nardi, B. A., Schiano, D. J., Gumbrecht, M., \& Swartz, L. (2004). Why we blog. Commun. ACM, 47(12), 41-46.

[25] Stephens, M. (2008). The Pragmatic Biblioblogger: Examining the Motivations and Observations of Early Adopter Librarian Bloggers. Internet Reference Services Quarterly, 13(4), 311-345.

[26] Svensson, P. (2010). The Landscape of Digital Humanities. Digital Humanities Quarterly, 4(1).

[27] Torres-Salinas, D., Cabezas-Clavijo, Á., Ruiz-Pérez, R., \& López-Cózar, E. D. (2011). State of the library and information science blogosphere after social networks boom: A metric approach. Library \& Information Science Research, 33(2), 168-174.

[28] Vanclay, F., Lane, R., Wills, J., Coates, I. A. N., \& Lucas, D. (2004). "Committing to Place" and Evaluating The Higher Purpose: Increasing Engagement in Natural Resource Management Through Museum Outreach and Educational Activities. Journal of Environmental Assessment Policy \& Management, 6(4), 539-564.

[29] Webster, J. G., \& Ksiazek, T. B. (2012). The Dynamics of Audience Fragmentation: Public Attention in an Age of Digital Media. Journal of Communication, 62(1), 39-56. 